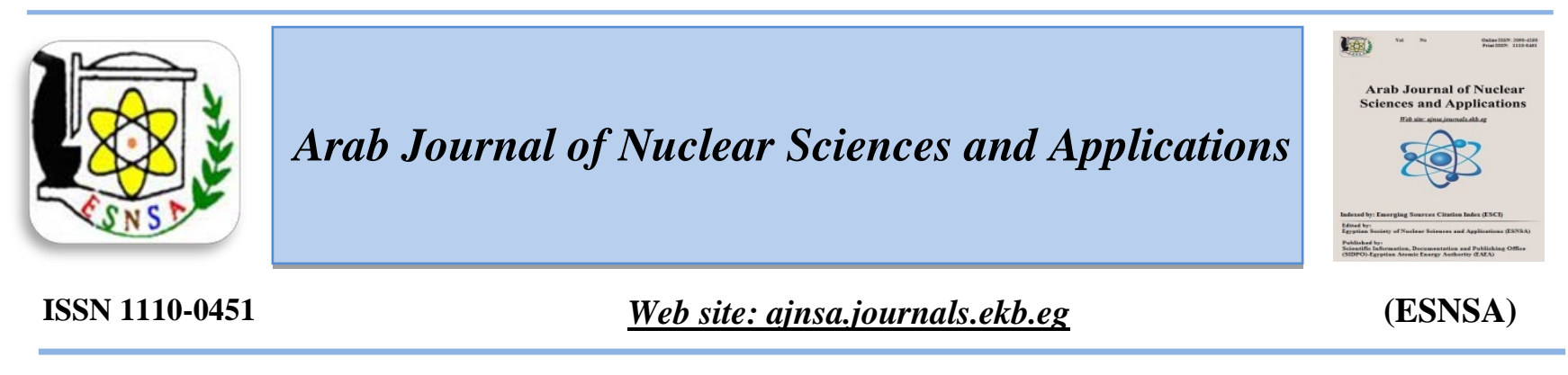

\title{
Radioiodination and Biological Evaluation of Tizanidine as a Potential Brain Imaging Agent
}

\author{
M.A. Mourad ${ }^{\text {a }}$ H. Abd El-Aziz ${ }^{\text {b A.M. Amin }}{ }^{\text {b }}$, G.G. Mohamed ${ }^{\text {c }}$ and S.A. Abo El-Enein ${ }^{\text {d }}$ \\ ${ }^{(a)}$ Centre of Radiation Oncology and Nuclear Medicine, Kasr Al-Ainy, Cairo, Egypt \\ (b) Labeled Compounds Department, Hot Labs Center, Atomic Energy Authority, Cairo, Egypt \\ ${ }^{(c)}$ Chemistry Department, Faculty of Science, Cairo University, 12613, Giza, Egypt \\ ${ }^{(d)}$ Chemistry Department, Faculty of Science, Ain Shams University, Cairo, Egypt
}

\begin{abstract}
Labeling was carried out by direct iodination of tizanidine $(100 \mu g)$ with radioiodine $\left({ }^{125} \mathrm{I}\right)$ in a fast single step at room temperature, to produce ${ }^{125}$ I-tizanidine $\left({ }^{125}\right.$ I-TZN). $50 \mu$ g chloramine-T (CAT) was used as an oxidizing agent to oxidize the iodide ion to the iodonium ion, at neutral $\mathrm{pH}=7$ within $15 \mathrm{~min}$. A high radiochemical yield of $92.8 \% \pm 0.1$ was obtained. ${ }^{125} \mathrm{I}$-TZN was stable for $2 \mathrm{~h}$ without detection of any by-products in the reaction mixture. The partition coefficient value of ${ }^{125}$ I-TZN was $2.21 \pm 0.02$, showing that it is very lipophilic and can easily cross the blood brain barrier. Biodistribution studies and in vivo imaging showed that the initial brain uptake correlated fairly well with the brain-binding affinity of the compound. The brain uptake of ${ }^{125}$ I-TZN was as high as $5.2 \%$ and $8.0 \%$ in biodistribution studies and in vivo imaging at 120 min post injection, respectively. Thus, ${ }^{125}$ I-TZN is promising in radioreceptor assays for brain imaging.
\end{abstract}

Keywords: Radioiodination - Tizanidine - Biodistribution- Brain Imaging - SPECT

\section{Introduction}

Nuclear medicine imaging involves the detection and spatial mapping of the radiation emitted by a radiopharmaceutical labeled with a specific radionuclide. The objectives of a nuclear medicine scan of the brain may include, for example, the detection of lesions, the evaluation of regional cerebral blood flow (rCBF), or the quantitative determination of a particular metabolic process such as the rate of regional glucose utilization [1]. The development of emission tomography is a good example of the fusion of a number of scientific and medical disciplines to produce an effective imaging technique. There are two different techniques of emission tomography: positron emission tomography (PET), based on radionuclides which decay by positron emission, and single photon

emission computed tomography (SPECT) which is based on radionuclides which emit gamma rays or $\mathrm{X}$-rays. While PET has some inherent technical advantages over SPECT, the economic reality dictates that SPECT is usually the only technique available in routine clinical practice. Recent innovations in the design of multi-head SPECT systems, which allow them to detect positronemitting radionuclides, have diminished the sharp distinction between the two techniques [2].

Corresponding Author: mai.adel89@gmail.com

DOI: 10.21608/ajnsa.2018.2178.1017

(C) Scientific Information, Documentation and Publishing Office (SIDPO)-EAEA 
Isotopes of iodine have, for decades, played a fundamental role in biomedical research and in clinical practice. The diversity of decay schemes available for the various isotopes of iodine has allowed a wide range of medical applications. For example, iodine-125 is a convenient radionuclide for in vitro applications because it has a long halflife (about 59 days) and emits low-energy photons (35 keV), while ${ }^{131} \mathrm{I}$ is more suitable for in vivo imaging because of its high-energy gamma radiation (364 keV) [3]. Moreover, iodine-123 has the decay properties required for diagnostic in vivo studies [4]. Synthetic approaches for the radioiodination of compounds generally follow established conventional chemical methods [5]. Direct methods involve the use of CAT [6], iodogen [7]and lactoperoxidase [8]. Indirect methods, which have been utilized, include conjugation of the radioiodinating reagent such as Bolton-Hunter reagent [9], N-succinimidyl paraiodobenzoate [10] and radioiodinated tyramine [11].

Tizanidine hydrochloride (5-chloro-4-(2imidazolin-2-ylamino)-2,1,3-benzothiadiazol hydrochloride) belongs to the class of organic compounds known as benzothiadiazoles. These are heterocyclic aromatic compounds containing a benzene ring fused to a thiadiazole ring (Fig. (1)). TZN is a centrally acting $\alpha_{2}$-adrenergic agonist with an average blood-brain barrier penetration probability of 0.8592 [12], which is used as a systemic muscle relaxant. The present study deals with the iodine-125 labeling of TZN to obtain a novel agent for brain imaging. Factors affecting the labeling yield were studied in detail.

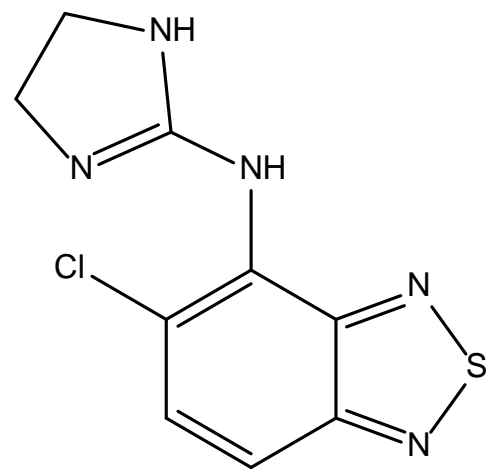

Fig. (1): Chemical structure of TZN

\section{Experimental \\ Chemicals}

Arab J. Nucl. Sci. \& Applic. Vol. 51, No.2 (2018)
All chemicals and laboratory reagents used during this work were of the highest purity analytical grade. Double distilled water was used in all experiments. TZN was kindly supplied by the National Organization for Drug Control and Research (NODCAR), Giza, Egypt. CAT was purchased from Aldrish Chemical Company, China. Radioactive iodine-125 (NaI) with 370 $\mathrm{MBq}$ activity from Izotop Company, Budapest. Radioactive iodine-131 (NaI) with 1.85 GBq activity was supplied by the Radioisotope Production Facility, Egyptian Atomic Energy Authority, Egypt. Citric acid (pH 2 and 4), phosphate (pH 7) and bicarbonate (pH 9 and 11) buffers were prepared for $\mathrm{pH}$ adjustment. Silica gel thin-layer chromatography (SG-TLC) was purchased from Merck, Germany. Radioactivity was measured by means of a single detector $\gamma$ counter (Hidex model).

\section{Radiolabeling of TZN}

Radiolabeling of TZN was carried out by adding a suitable concentration of TZN to an appropriate quantity of freshly prepared CAT and the $\mathrm{pH}$ of the reaction mixture was varied $(\mathrm{pH} 2-11)$ using different buffer systems. Carrier-free $\mathrm{Na}^{125} \mathrm{I}$ was added to this mixture [13], followed by vortex and then the reaction mixture was kept in a water bath for different time intervals. The reaction was quenched by the addition of sodium thiosulfate solution [14].

\section{Determination of radiochemical yield}

The radiochemical yield of the ${ }^{125} \mathrm{I}-\mathrm{TZN}$ was determined using aluminum-backed silica gel-60 sheet $(20 \times 20 \mathrm{~cm})$. The SG-TLC strips $(1.5 \mathrm{~cm}$ width, $14 \mathrm{~cm}$ length) were marked $2 \mathrm{~cm}$ from the base and lined into $1 \mathrm{~cm}$ fragments using a nonpointed pencil. A reaction product sample $(5 \mu \mathrm{L})$ was spotted 5 times repeatedly with a micropipette, then the strip was developed in an ascending manner in a closed cylinder filled with chloroformethanol mixture $(9: 1 \mathrm{v} / \mathrm{v})$. After complete development, the strips were dried, cut into $1 \mathrm{~cm}$ pieces and counted in a well-type $\gamma$-scintillation counter. The radiochemical yield was calculated as the mean value of three replicate measurements.

\section{Determination of radiochemical purity}

The radiochemical purity of ${ }^{125} \mathrm{I}-\mathrm{TZN}$ was determined by direct injection of $5-10 \mu \mathrm{L}$, of the reaction mixture at the optimum conditions for obtaining the highest radiochemical yield, into RP- 
C18 column of a Shimadzu high performance liquid chromatography (HPLC) with methanol: acetonitrile: pH 6.6 phosphate buffer (15:40:45 $\mathrm{v} / \mathrm{v}$ ) as mobile phase using a UV detector operating at $307 \mathrm{~nm}$. The mobile phase was fed at a rate of $1.0 \mathrm{~mL} / \mathrm{min}$. The fractions were collected and counted using NaI/TI crystal connected to gamma counter [15].

\section{In vitro stability}

The reaction mixture was prepared in conditions which gave the highest radiochemical yield. The in vitro stability of ${ }^{125} \mathrm{I}-\mathrm{TZN}$ was studied at different time intervals (1, 2, 4, 8 and $24 \mathrm{~h})$ and the radiochemical yield was calculated at each time.

\section{Lipophilicity}

The partition coefficient of ${ }^{125}$ I-TZN was determined in the system 1-octanol and phosphate buffer $(0.025 \mathrm{~mol} / \mathrm{L}$ at $\mathrm{pH} 7.4)$ at equal phase volumes. Experiments were performed in a centrifuge tube. The mixture was vortexed at room temperature for $1 \mathrm{~min}$ and then centrifuged at 5000 rpm for $5 \mathrm{~min}$. After that, $100 \mu \mathrm{L}$ samples from each phase were pipetted into other test tubes and counted in a $\gamma$-counter. The measurement was repeated three times. The partition coefficient was expressed as $\log \mathrm{P}$ according to the following equation [16]:

$$
\log p_{\text {oct } / \text { buf }}=\log \left(\frac{[\text { solute }]_{\text {octanol }}}{[\text { solute }]_{\text {phosphate buffer }}}\right)
$$

\section{In vivo biodistribution studies}

The study was approved by the Animal Ethics Committee, Labeled Compounds Department, and was in accordance with the guidelines set out by the Egyptian Atomic Energy Authority. The animals, normal Swiss Albino male mice (25-30 g), were intravenously injected with $200 \mu \mathrm{L}{ }^{125} \mathrm{I}$ TZN via the tail vein and kept alive in metabolic cage for different intervals of time under normal conditions. Three mice were used for each experiment. The mice were sacrificed at 10,60 , 120 and 240 min post injection. Samples of fresh blood, bones and muscles were collected in preweighed vials and counted. The weights of blood, bones and muscles were assumed to be 7 , 10 and $40 \%$ of the total body weight, respectively [17]. Radioactivity percentage in each tissue/organ was measured using $\gamma$-scintillation detector. The brain/blood ratio was calculated from the corresponding percentage of the injected dose per gram $(\% \mathrm{ID} / \mathrm{g})$ values.

\section{In vivo SPECT imaging}

Mice were anaesthetized by intravenous injection of diazepam $(5 \mu \mathrm{L} / \mathrm{g})$, then injected with the ${ }^{131} \mathrm{I}$ TZN compound (containing $37 \mathrm{MBq}$ ) via the caudal vein. Each mouse was positioned for imaging at the chosen time intervals $(10,60,120$ and $240 \mathrm{~min}$ ). The mice were imaged in supine and feet first position with 180 head configuration for $10 \mathrm{~min}$ acquisition duration using high energy general all purpose-parallel (HEGAP-Par) collimator. The obtained images were planner with $128 \times 128$ matrix.

\section{Results and Discussion}

Effect of substrate concentration

The influence of TZN concentration on the percentage of radiochemical yield of ${ }^{125} \mathrm{I}-\mathrm{TZN}$ for $15 \mathrm{~min}$ at room temperature (about $25 \pm 3^{\circ} \mathrm{C}$ ) was investigated using $50 \mu \mathrm{g}$ CAT with $200 \mu \mathrm{L}$ phosphate buffer ( $\mathrm{pH} 7)$ as shown in Fig. (2). The results indicate that the radiochemical yield increases with increasing the concentration of TZN till reaching $92.8 \% \pm 0.1$ at $100 \mu \mathrm{g}$ TZN. Further increase in concentration, show a slight decrease in the percent of the radiochemical yield. This may be attributed to the fact that $100 \mu \mathrm{g}$ of TZN is enough to capture the entire generated iodonium ions as a result of the oxidation of the radioactive iodide $\left({ }^{125} \mathrm{I}^{-}\right)$at $50 \mu \mathrm{g}$ CAT [18].

\section{Effect of CAT concentration}

Radioiodination of organic molecules has been performed using a mild oxidizing agent such as CAT, which decomposes to hypochlorite anion that acts as an oxidizing agent, transforming iodine from $\mathrm{I}^{-}$to the oxidative state $\mathrm{I}^{+}$. The radioiodination of TZN is highly dependent on the concentration of CAT. Fig. (3) shows that the radiochemical yield of ${ }^{125} \mathrm{I}$-TZN increased to 92.8 $\% \pm 0.1$ at $50 \mu \mathrm{g}$ CAT. Increasing the CAT amount above $50 \mu \mathrm{g}$ led to a decrease in the radioiodination yield due to the formation of undesirable oxidative by-products like chlorination, polymerization and denaturation of TZN [19].

\section{Effect of reaction temperature}

The radioiodination of TZN was carried out by studying the effect of the reaction temperature (25$100{ }^{\circ} \mathrm{C}$ ) using $100 \mu \mathrm{g}$ TZN and $50 \mu \mathrm{g}$ CAT at $\mathrm{pH} 7$

Arab J. Nucl. Sci. \& Applic. Vol. 51, No.2 (2018) 
for $15 \mathrm{~min}$. The data indicated that the reaction temperature is a significant factor that affects the labeling yield. Fig. (4) shows that the maximum radiochemical yield was $\quad 94.4 \%$ at $80{ }^{\circ} \mathrm{C}$. Nevertheless, there was no need to raise the reaction temperature to such a high temperature while the radiochemical yield was good enough at room temperature $(92.8 \% \pm 0.1)$ and too close to the maximum yield. Hence, room temperature was considered the optimum temperature.

\section{Effect of $p H$ of reaction medium}

The variation of the radiochemical yield of ${ }^{125} \mathrm{I}$ TZN with CAT as a function of $\mathrm{pH}$ was investigated in the $\mathrm{pH}$ range from 2 to 11 . Fig. (5) shows that the maximum radiochemical yield of
${ }^{125} \mathrm{I}-\mathrm{TZN}(92.8 \% \pm 0.1)$ was obtained at $\mathrm{pH} 7$. At acidic $\mathrm{pH}$, the radiochemical yield of ${ }^{125} \mathrm{I}$-TZN decreased and this may be attributed to the predominance of ICl species which have low oxidation potential less than $\mathrm{HOCl}$ [20]. At alkaline $\mathrm{pH}$, the yield also decreased markedly reaching $36.2 \%$, as a result of decreasing $\mathrm{HOI}$ which was responsible for the electrophilic substitution reaction.

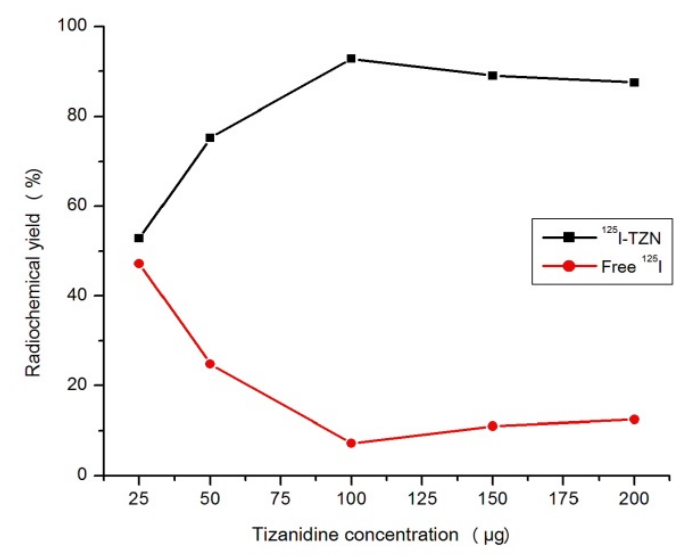

Fig. (2): The radiochemical yield of ${ }^{125}$ I-TZN as a function of substrate amount (x $\mu \mathrm{g}$ TZN, $50 \mu \mathrm{g}$ CAT, about $3.7 \mathrm{MBq}$ $\mathrm{Na}^{125} \mathrm{I}, \mathrm{pH} 7$, at room temperature for $15 \mathrm{~min}$ )

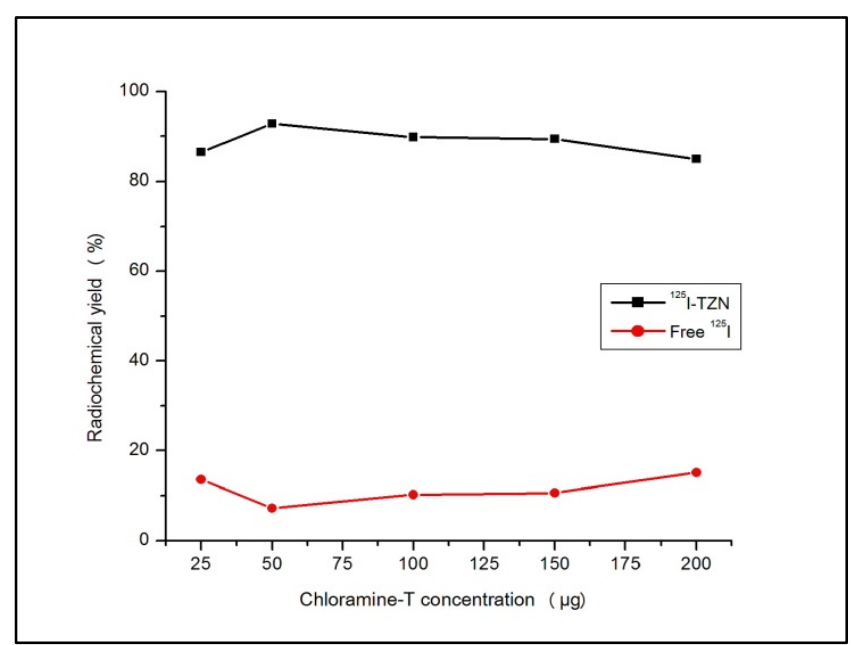

Fig. (3): The radiochemical yield of ${ }^{125} \mathrm{I}-\mathrm{TZN}$ as a function of CAT amount (100 $\mu \mathrm{g}$ TZN, $\mathrm{x} \mu \mathrm{g}$ CAT, about $3.7 \mathrm{MBq} \mathrm{Na}^{125} \mathrm{I}$, pH 7, at room temperature for $15 \mathrm{~min}$ ) 


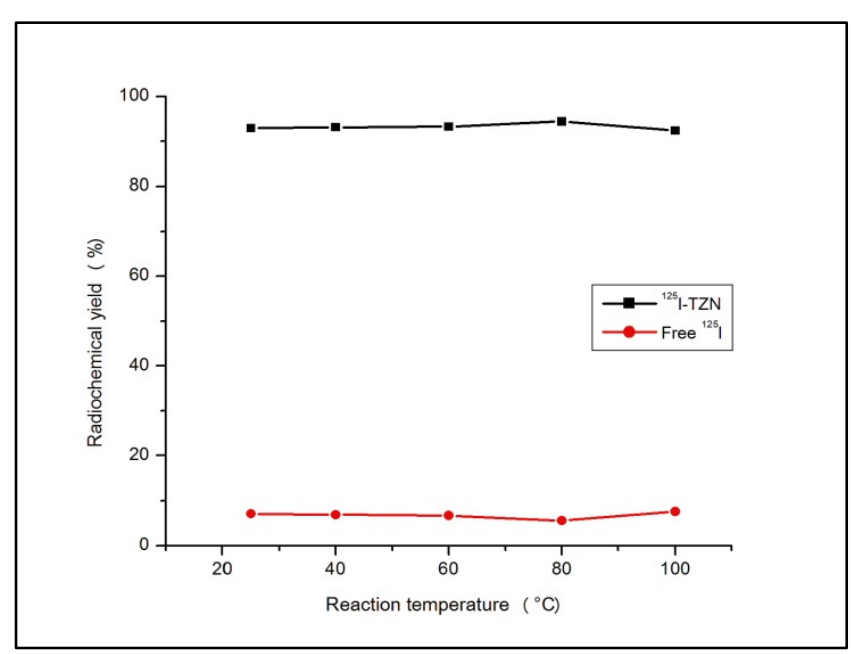

Fig. (4): Effect of temperature on the radiochemical yield of ${ }^{125} \mathrm{I}-\mathrm{TZN}\left(100 \mu \mathrm{g}\right.$ TZN, $50 \mu \mathrm{g}$ CAT, about $3.7 \mathrm{MBq} \mathrm{Na}^{125} \mathrm{I}$, pH 7 , at $\mathrm{x}^{\circ} \mathrm{C}$ for $\left.15 \mathrm{~min}\right)$

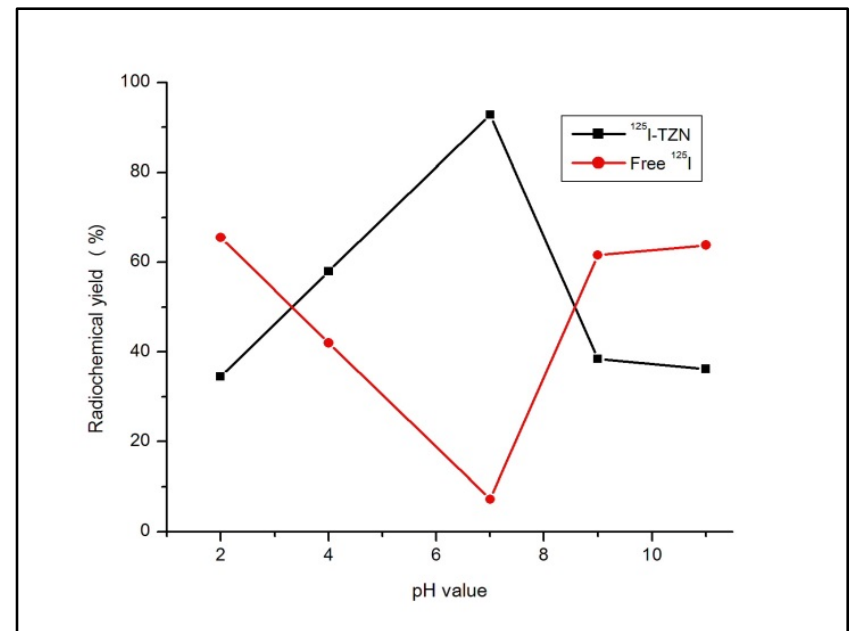

Fig. (5): Effect of pH on the radiochemical yield of ${ }^{125} \mathrm{I}-\mathrm{TZN}\left(100 \mu \mathrm{g}\right.$ TZN, $50 \mu \mathrm{g}$ CAT, about $3.7 \mathrm{MBq} \mathrm{Na}^{125} \mathrm{I}$, pH x, at room temperature for $15 \mathrm{~min}$ ) 


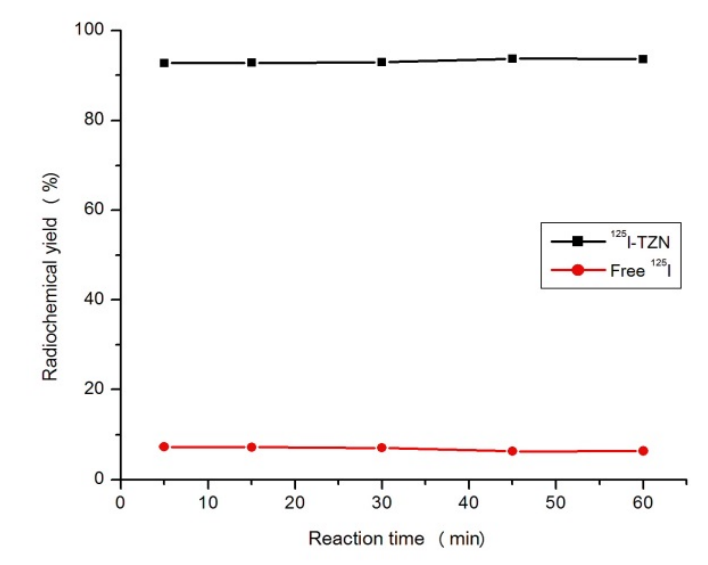

Fig. (6): The radiochemical yields of ${ }^{125} \mathrm{I}-\mathrm{TZN}$ as a function of reaction time (100 $\mu \mathrm{g}$ TZN, $50 \mu \mathrm{g}$ CAT, about $3.7 \mathrm{MBq}$ $\mathrm{Na}^{125} \mathrm{I}, \mathrm{pH} 7$, at room temperature for $\mathrm{x}$ min)

\section{Effect of reaction time}

It is clear from Fig. (6) that the radiochemical yield increased with time till reaching $93.7 \%$ after 45 min, but this was considered a time consuming. Thus, only $15 \quad \mathrm{~min}$ with $92.8 \% \quad \begin{array}{llll}0.1 & 0\end{array}$ radiochemical yield would be sufficient for radiolabeling procedure and considered the optimum reaction time.

\section{In vitro stability}

The stability of ${ }^{125} \mathrm{I}-\mathrm{TZN}$ was studied in order to determine the suitable period of injection to avoid the formation of undesired products which would result from the radiolysis of the labeled compound. Table (1) shows that ${ }^{125} \mathrm{I}-\mathrm{TZN}$ is stable for $2 \mathrm{~h}$ and its storage for a long time $(24 \mathrm{~h})$ causes its decomposition and a decrease of its yield to 75.9 $\%$.

\section{Lipophilicity}

The partition coefficient value of ${ }^{125} \mathrm{I}-\mathrm{TZN}$ was $2.21 \pm 0.02$, showing that ${ }^{125} \mathrm{I}-\mathrm{TZN}$ is very lipophilic and can easily cross the blood-brain barrier to the target receptors.

\section{HPLC analysis}

A radiochromatogram for ${ }^{125} \mathrm{I}-\mathrm{TZN}$ obtained after HPLC separation on RP-C18 column at optimum conditions is shown in Fig. (7). Three peaks were obtained; the first peak at 2 min corresponds to TZN while the second peak at 5 min corresponds to the free iodide and the third peak at $12 \mathrm{~min}$ corresponds to ${ }^{125} \mathrm{I}-\mathrm{TZN}$. The eluted fractions containing the labeled compound were pooled together and evaporated to dryness. The residue was dissolved in physiological saline and sterilized by filtration through $0.22 \mu \mathrm{m}$ Millipore filter, and the ${ }^{125}$ I-TZN is then suitable for use in biodistribution studies and SPECT imaging.

Table (1): In vitro stability of ${ }^{125} \mathrm{I}-\mathrm{TZN}$ at optimum labeling conditions (100 $\mu$ g TZN, $50 \mu$ g CAT, about 3.7 MBq Na ${ }^{125} \mathrm{I}$, pH 7, at room temperature for 15 min)

\begin{tabular}{|c|c|}
\hline Time post labeling (h) & $\begin{array}{c}{ }^{125} \mathrm{I}-\mathrm{TZN} \text { labeling yield } \\
(\%)\end{array}$ \\
\hline 1 & $90.2 \pm 0.3$ \\
\hline 2 & $89.9 \pm 1.0$ \\
\hline 4 & $76.5 \pm 0.2$ \\
\hline 8 & $76.1 \pm 0.2$ \\
\hline 24 & $75.9 \pm 0.9$ \\
\hline
\end{tabular}

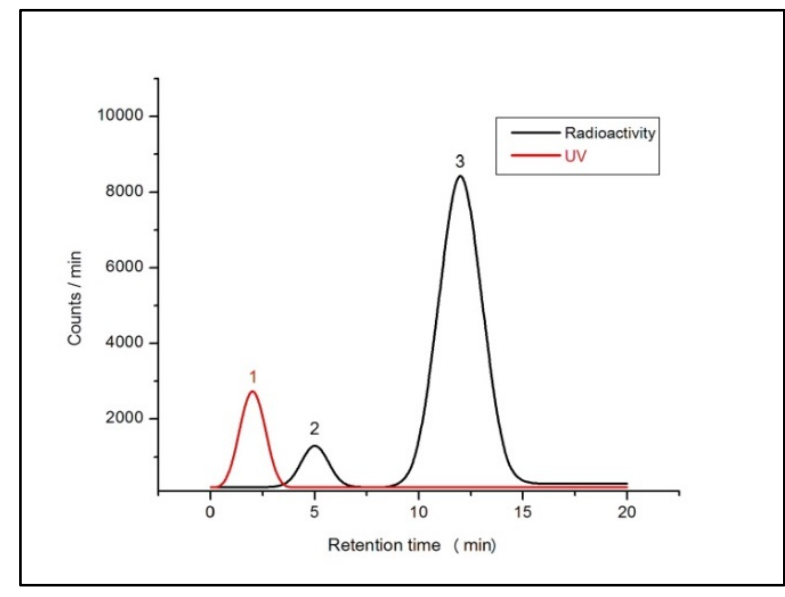

Fig. (7): HPLC elution profile of ${ }^{125}$ I-TZN mixture at optimum labeling conditions (peak (1) for TZN, peak (2) for $\mathrm{Na}^{125} \mathrm{I}$, peak (3) for ${ }^{125} \mathrm{I}$ TZN)

Biodistribution studies 
Biodistribution study of ${ }^{125} \mathrm{I}-\mathrm{TZN}$ in normal mice showed high brain uptake $(1.7 \%)$ at $10 \mathrm{~min}$ post injection, indicating the ability of the tracer to penetrate the blood-brain barrier as fast as the tracer injected. The clearance rate from the brain tissues was slow, as shown in Table (2), indicating that the tracer was bound to $\alpha_{2}$-adrenergic receptors in the brain. The renal uptake is higher than the hepatic uptake indicating that the labeled compound excreted mainly through the urinary system. The low activity located in the thyroid gland indicates that ${ }^{125} \mathrm{I}-\mathrm{TZN}$ is stable in vivo against biological decomposition. The ability and the efficiency of the labeled compound to be used as a brain imaging agent depends greatly on the ratio of the activity hold by the brain to the background activity (blood activity). The high brain-to-blood ratio, which is due to the high blood clearance, makes the radiolabeled TZN suitable for use as a brainimaging agent.

\section{In vivo SPECT imaging}

In vivo SPECT brain scans of Albino mouse injected with ${ }^{131}$ I-TZN were shown in Fig. (8) in order to visualize the drug localization in the brain. These images were taken at four different time intervals $(10,60,120$ and $240 \mathrm{~min}$ post intravenous injection), but it was not highly clear due to the small size of the mouse (a mouse is 3000 times smaller in weight than a human). After
10 min of injection, there was a significant ${ }^{131}$ ITZN percentage reached to the brain (1.8\%), and it increased to the maximum (8.0\%) after $120 \mathrm{~min}$ post injection, then decreased again to $5.1 \%$ after 240 min of injection as shown in Table (3).

\section{Conclusion}

TZN was labeled with radioactive iodine by direct electrophilic substitution reaction and the produced tracer was evaluated radiochemically to select the optimum conditions required to produce a high radiolabeling yield. TZN was efficiently labeled with a radiochemical yield of $92.8 \% \pm 0.1$ when its amount was $100 \mu \mathrm{g}$ in the presence of $50 \mu \mathrm{g}$ CAT as oxidizing agent at $\mathrm{pH} 7$ and the reaction mixture was incubated for $15 \mathrm{~min}$ at room temperature. The radiolabeled TZN was intravenously injected in mice and the brain uptake was $5.2 \%$ and $8.0 \%$ at 120 min post injection in biodistribution studies and SPECT imaging, respectively, which indicates that this labeled compound can be used as a radiopharmaceutical imaging agent.

Table (2): Biodistribution of ${ }^{125} \mathrm{I}$-TZN (in \%) in normal mice at different time intervals

\begin{tabular}{|c|c|c|c|c|}
\hline \multirow{2}{*}{$\begin{array}{l}\text { Organs and } \\
\text { body fluids }\end{array}$} & \multicolumn{4}{|c|}{ Time post injection(min) } \\
\hline & 10 & 60 & 120 & 240 \\
\hline Brain & $1.7 \pm 0.5$ & $3.6 \pm 0.3$ & $5.2 \pm 0.2$ & $4.2 \pm 0.1$ \\
\hline Blood & $17.1 \pm 1.0$ & $9.5 \pm 0.7$ & $9.0 \pm 0.6$ & $7.5 \pm 0.2$ \\
\hline Liver & $16.1 \pm 0.8$ & $8.8 \pm 0.6$ & $8.3 \pm 0.4$ & $7.6 \pm 0.3$ \\
\hline Intestine & $12.9 \pm 0.4$ & $18.2 \pm 0.9$ & $11.6 \pm 1.1$ & $9.3 \pm 1.3$ \\
\hline Stomach & $5.3 \pm 0.4$ & $7.2 \pm 0.7$ & $16.5 \pm 1.0$ & $15.1 \pm 0.5$ \\
\hline Lungs & $4.4 \pm 0.2$ & $0.4 \pm 0.2$ & $0.5 \pm 0.1$ & $0.7 \pm 0.1$ \\
\hline Heart & $1.3 \pm 0.1$ & $0.4 \pm 0.1$ & $0.4 \pm 0.1$ & $0.4 \pm 0.1$ \\
\hline Kidneys & $13.5 \pm 0.3$ & $10.4 \pm 0.4$ & $9.2 \pm 0.4$ & $9.6 \pm 0.2$ \\
\hline Spleen & $2.9 \pm 0.1$ & $0.2 \pm 0.1$ & $0.2 \pm 0.1$ & $0.3 \pm 0.1$ \\
\hline Muscles & $7.5 \pm 0.3$ & $6.9 \pm 0.4$ & $4.0 \pm 0.2$ & $4.4 \pm 0.2$ \\
\hline Bones & $1.3 \pm 0.3$ & $6.9 \pm 0.2$ & $5.8 \pm 0.1$ & $8.7 \pm 0.1$ \\
\hline Thyroid & $0.1 \pm 0.05$ & $0.1 \pm 0.05$ & $0.1 \pm 0.05$ & $0.1 \pm 0.05$ \\
\hline Urine & $16.0 \pm 0.8$ & $27.3 \pm 0.6$ & $29.2 \pm 1.2$ & $32.1 \pm 2.4$ \\
\hline Brain* & $4.3 \pm 0.5$ & $9.6 \pm 0.3$ & $13.2 \pm 0.2$ & $9.7 \pm 0.1$ \\
\hline Blood* & $10.7 \pm 1.0$ & $6.4 \pm 0.7$ & $5.5 \pm 0.6$ & $5.0 \pm 0.2$ \\
\hline$(\mathrm{Br} / \mathrm{Bl})^{*}$ & 0.4 & 1.5 & 2.4 & 1.9 \\
\hline
\end{tabular}

Table (3): The injected dose percentage of ${ }^{131}$ I-TZN in some organs according to SPECT imaging 


\begin{tabular}{|c|c|c|c|c|}
\hline \multirow{2}{*}{ Organs } & \multicolumn{4}{|c|}{ Time post injection (min) } \\
\cline { 2 - 5 } & 10 & 60 & 120 & 240 \\
\hline Brain & 1.8 & 5.5 & 8.0 & 5.1 \\
\hline Liver & 5.1 & 19.9 & 39.4 & 25.3 \\
\hline Bladder & 2.1 & 10.4 & 14.3 & 7.4 \\
\hline
\end{tabular}
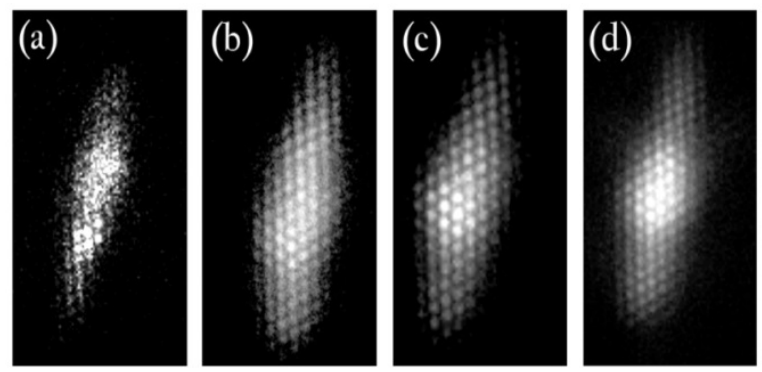

Fig. (8): SPECT brain scan of a mouse injected with ${ }^{131}$ I-TZN at four different time intervals (10, 60, 120 and 240 min from (a) to (d))

\section{References}

1- Diksic, M. and Reba, R.C. Radiopharmaceuticals and Brain Pathology Studied with PET and SPECT, CRC press, Inc., US(1991).

2- Duncan, R. SPECT Imaging of the Brain, Springer Science \& Business Media Dordrecht, UK (1997).

3- Wilbur, D.S. Radiohalogenation of Proteins: An Overview of Radionuclides, Labeling Methods, and Reagents for Conjugate Labeling, Bioconjug. Chem., 3, 433-470(1992).

4- Stocklin, G. Bromine-77 and Iodine-123 Radiopharmaceuticals, Appl. Radiat. Isot., 28, 131148(1977).

5- Coenen, H.H., Mertens, J. and Maziere, B. Radioionidation Reactions for Pharmaceuticals, Springer Netherlands(2006).

6- Sanad, M.H. and Challan, S.B. Radioiodination and Biological Evaluation of Rabeprazole as a Peptic Ulcer Localization Radiotracer, Radiochemistry, 59 (3), 307-312(2017).

7- Kumar, C., Subramaniam, S. and Samuel, G. Evaluation of Radioiodinated Curcumin for its Potential as a Tumor-Targeting Radiopharmaceutical, J. Radiat. Cancer Res., 7 (4), 112-116(2016).

8- Runnegar, M., Berndt, N., Kong, S.M., Lee, E.Y.C. and Zhang, L.F. In Vivo and In Vitro Binding of Microcystin to Protein Phosphatase 1 and 2A, Biochem. Biophys. Res. Commun., 216 (1), 162169(1995).

9- Park, J.J., Lee, T.S., Kang, J.H., Song, R. and Cheon, G.J. Radioiodination and Biodistribution of Quantum Dots using Bolton-Hunter Reagent, Appl. Radiat. Isot., 69 (1), 56-62(2011).

10- Malmberg, J., Strandgard, J., Tolmachev, V., Orlova, A. and Andersson, K. Protein Interactions with the HER2 Receptor can have Different Characteristics Depending on the Hosting CellLine, J. Nucl. Med., 53 (1), 1713(2012).

Arab J. Nucl. Sci. \& Applic. Vol. 51, No.2 (2018)
11- Reist, C.J., Archer, G.E., Kurpad, S.N., et al, Tumor-Specific Anti-Epidermal Growth Factor Receptor Variant III Monoclonal Antibodies: Use of the Tyramine-Cellobiose Radioiodination Method Enhances Cellular Retention and Uptake in Tumor Xenografts, Cancer Res., 55 (19), 4375-4382(1995).

12- Cheng, F., Li, W., Zhou, Y., Shen, J., Wu, Z., Liu, G., Lee, P.W. and Tang, Y. admetSAR: A Comprehensive Source and Free Tool for Assessment of Chemical ADMET Properties, J. Chem. Inf. Model., 52 (11), 3099-3105(2012).

13- Coenen, H.H., Moerlein, S.M. and Stocklin, G. No-Carrier-Added Radiohalogenation Methods with Heavy Halogens, Radiochim. Acta, 34, 4768(1983).

14- Greenwood, N. and Earnshaw, A. Chemistry of the Elements, $2^{\text {nd }} \quad$ Ed., Butterworth-Heinemann, Oxford(1997).

15- Nimje, H., Wate, S.P., Dharkar, D.P. and Razdan, R. Simultaneous RPHPLC Determination of Nimesulide and Tizanidine in Tablets, Indian $J$. pharm. Sci., 69 (2), 281-283(2007).

16- Liu, F.E.I., Youfeng, H.E. and Luo, Z. Study of ${ }^{99 m}$ Tc Labelled Way Analogues for 5-HT $1 \mathrm{~A}$ Receptor Imaging, IAEA, Technical Reports Series No. 426, 37(2004).

17- Amin, A.M., Sanad, M.H. and Abd-Elhaliem, S.M. Radiochemical and Biological Characterization of ${ }^{99 m}$ Tc-Piracetam for Brain Imaging, Radiochemistry, 55 (6), 624-628(2013).

18- El-Azony, K.M., El-Mohty, A.A., Killa, H.M., Seddik, U. and Khater, S.I. (2009) An Investigation of the ${ }^{125}$ I-radioiodination of Colchicine for Medical Purposes, J. Labelled Compd. Rad., 52 (1), 1-5.

19- El-Azony, K.M. Preparation of ${ }^{125}$ I-celecoxib with High Purity as a Possible Tumor Agent, $J$. Radioanal. Nucl. Ch., 285 (2), 315-320(2010). 
20- Bearer, C.F., Knapp, R.D., Kaumann, A.J., Swartz, T.L. and Birnbaumer, L. Iodohydroxybenzylpindolol: Preparation, Purification, Localization of its Iodine to the
Indole Ring, and Characterization as a Partial Agonist, Mol. Pharmacol., 17 (3), 328-338(1980). 